Article

\title{
Delayed Antibiotic Prescription by General Practitioners in the UK: A Stated-Choice Study
}

\author{
Liz Morrell 1,*(D), James Buchanan 1,2,3 ${ }^{1}$, Laurence S. J. Roope 1,2,3, Koen B. Pouwels ${ }^{1,2} \mathbb{D}^{\text {, }}$ \\ Christopher C. Butler 2,4 ${ }^{\text {, Benedict Hayhoe }}{ }^{5}$, Michael V. Moore ${ }^{6} \mathbb{D}$, Sarah Tonkin-Crine ${ }^{2,4}(\mathbb{D}$, \\ Monsey McLeod 7,8,9 ${ }^{D}$, Julie V. Robotham ${ }^{10}$, A. Sarah Walker ${ }^{2,3,11}$, Sarah Wordsworth ${ }^{1,2,3}$ and \\ on behalf of the STEPUP team ${ }^{\dagger}$
}

1 Health Economics Research Centre, Nuffield Department of Population Health, University of Oxford, Oxford OX3 7LF, UK; james.buchanan@dph.ox.ac.uk (J.B.); laurence.roope@dph.ox.ac.uk (L.S.J.R.); koen.pouwels@ndph.ox.ac.uk (K.B.P.); sarah.wordsworth@dph.ox.ac.uk (S.W.)

2 NIHR Health Protection Research Unit in Healthcare Associated Infections and Antimicrobial Resistance, University of Oxford, Oxford OX2 6GG, UK; christopher.butler@phc.ox.ac.uk (C.C.B.);

sarah.tonkin-crine@phc.ox.ac.uk (S.T.-C.); sarah.walker@ndm.ox.ac.uk (A.S.W.)

3 NIHR Biomedical Research Centre Oxford, John Radcliffe Hospital, University of Oxford, Oxford OX3 9DU, UK

4 Nuffield Department of Primary Care Health Sciences, University of Oxford, Oxford OX2 6GG, UK

5 Department of Primary Care and Public Health, School of Public Health, Imperial College London, London W2 1PG, UK; b.hayhoe@imperial.ac.uk

6 Primary Care, Population Sciences and Medical Education, Faculty of Medicine, University of Southampton, Southampton SO17 1BJ, UK; mvm198@soton.ac.uk

7 NIHR Health Protection Research Unit in Healthcare-Associated Infections and Antimicrobial Resistance, Imperial College London, London SW7 2AZ, UK; monsey.mcleod@nhs.net

8 Centre for Medication Safety and Service Quality, Pharmacy Department, Imperial College Healthcare NHS Trust, London W2 1NY, UK

9 NIHR Imperial Patient Safety Translational Research Centre, Imperial College London, London SW7 2AZ, UK

10 Modelling and Economics Unit, National Infection Service, Public Health England, London SE1 8UG, UK; julie.robotham@phe.gov.uk

11 Nuffield Department of Medicine, University of Oxford, Oxford OX3 7BN, UK

* Correspondence: liz.morrell@ndph.ox.ac.uk

+ Listed in Acknowledgements.

Received: 6 August 2020; Accepted: 14 September 2020; Published: 16 September 2020

check for updates

\begin{abstract}
Delayed antibiotic prescription in primary care has been shown to reduce antibiotic consumption, without increasing risk of complications, yet is not widely used in the UK. We sought to quantify the relative importance of factors affecting the decision to give a delayed prescription, using a stated-choice survey among UK general practitioners. Respondents were asked whether they would provide a delayed or immediate prescription in fifteen hypothetical consultations, described by eight attributes. They were also asked if they would prefer not to prescribe antibiotics. The most important determinants of choice between immediate and delayed prescription were symptoms, duration of illness, and the presence of multiple comorbidities. Respondents were more likely to choose a delayed prescription if the patient preferred not to have antibiotics, but consultation length had little effect. When given the option, respondents chose not to prescribe antibiotics in $51 \%$ of cases, with delayed prescription chosen in $21 \%$. Clinical features remained important. Patient preference did not affect the decision to give no antibiotics. We suggest that broader dissemination of the clinical evidence supporting use of delayed prescription for specific presentations may help increase appropriate use. Establishing patient preferences regarding antibiotics may help to overcome concerns about patient acceptance. Increasing consultation length appears unlikely to affect the use of delayed prescription.
\end{abstract}


Keywords: antibiotic resistance; choice experiment; primary care; general practice; delayed prescription; respiratory tract infection; stewardship; UK

\section{Introduction}

Reducing unnecessary antibiotic consumption is essential to reduce selection pressure on bacteria to develop resistance, and preserve the effectiveness of existing antibiotics [1,2]. In the UK, over $70 \%$ of antibiotics are prescribed in primary care [3], with 32 million antibiotic prescriptions dispensed in England in 2019 [4]. Much of this prescribing may be avoidable [5]. Many conditions treated in primary care, such as a substantial proportion of respiratory tract infections, are self-limiting and will resolve without antibiotics [5,6].

Amongst the strategies aimed at reducing antibiotic consumption, one option in primary care is delayed (or 'back-up') prescriptions. With this approach, a prescription is issued, but the patient is advised to wait, and only collect and begin taking the antibiotics if their symptoms worsen or do not resolve within a specified time period. This strategy can be used where the prescriber believes that antibiotics are not needed at the time, but has some clinical uncertainty as to whether the condition could deteriorate without antibiotics [7]. The delayed prescription approach has been shown in randomised trials in primary care to be effective in reducing consumption with little effect on symptom control or risk of complications, in respiratory tract infections [8-11], conjunctivitis [12] and urinary tract infections [13]. In the UK, the National Institute for Health and Care Excellence (NICE) has included the use of delayed prescriptions in its guidelines and Clinical Knowledge Summaries since 2008 [14-18]. The approach has the potential to provide reassurance to both prescribers [19] and patients [20]; it provides easier access to antibiotics should they be needed, but unnecessary consumption may be avoided if the illness follows its expected course. However, despite the supporting evidence, use of delayed prescriptions has been limited, with studies showing that only around $14 \%$ of prescriptions for common infections are delayed prescriptions [21,22]. To support more widespread implementation of this strategy for antimicrobial stewardship (in line with NICE guidelines), it is important to understand the barriers to using delayed prescriptions.

Studies to date on primary care physicians' attitudes to delayed prescription have been predominantly qualitative. These studies highlighted concerns over delayed prescriptions giving a potentially ambiguous message to patients, abdication of clinical responsibility and time taken in the consultation to explain a delayed prescription to the patient $[19,23-26]$. Our study aimed to develop this evidence base further by providing quantitative information on the relative importance of factors in the decision to use a delayed prescription as an alternative to an immediate prescription, with a focus on factors relating to the patient and the information discussed during the consultation.

Our study setting is primary care in the UK's National Health Service (NHS), where physicians (known as general practitioners (GPs)) make the majority of antibiotic prescribing decisions. We focus on respiratory tract infections (RTI), which are among the most common reasons for GP consultations [14,27], and account for a high proportion of antibiotic prescribing in primary care $[28,29]$. A recent analysis indicated that in the years $2013-2015$, at least $32 \%$ of primary care antibiotic prescriptions were for RTIs (including ear, nose and throat conditions) [28]; this represents over 11 million prescriptions in England at the 2018 prescribing level of 625 antibiotic prescriptions per 1000 patients [3]. In particular, we focus on cough and sore throat symptoms, for which much of the antibiotic prescribing is likely to be unnecessary [5,30,31]. There is therefore significant potential to reduce prescribing safely in this condition via broader use of delayed prescriptions where clinically appropriate.

We conducted a stated-choice study, a survey method widely used in health research [32-34]. The method asks respondents to make choices between alternative healthcare options, which are designed to require trade-offs between the attributes of these options. Our study presented a sample of 
UK GPs with fifteen hypothetical consulting scenarios they might encounter when a patient presents with an RTI, and asked them to choose whether they would give the patient an immediate or delayed prescription. In each case, respondents were also asked if they would prefer to give no antibiotic prescription. The scenarios consisted of eight attributes that described the presenting condition, the patient and the consultation (Table 1). Respondent choices were analysed using logistic regression, to determine the relative influence of the attributes on the prescribing decision. 
Table 1. Attributes and levels for the choice questions.

\begin{tabular}{|c|c|c|}
\hline Attribute $^{a}$ & Levels & Basis \\
\hline Symptoms the patient is experiencing ${ }^{b}$ & $\begin{array}{l}\text { 1: Sore and red throat, and swollen lymph nodes in the neck } \\
\text { 2: Productive cough and runny nose } \\
\text { 3: Sore throat, swollen lymph nodes in the neck, pyrexia and } \\
\text { purulent tonsils } \\
\text { 4: Productive cough, pyrexia and pain on breathing }\end{array}$ & $\begin{array}{l}\text { Two upper respiratory tract symptoms, and two lower, to allow } \\
\text { exploration of differences in perception of 'throat' and 'chest' } \\
\text { infections. Clinical guidelines [14,15], diagnostic criteria (such as } \\
\text { FeverPAIN [35]) and practising clinicians were consulted to } \\
\text { identify two plausible levels of severity for each, identified as } \\
\text { 'minor' ( } 1 \text { and } 2 \text { ) and 'serious' ( } 3 \text { and } 4 \text { ) throughout this paper. }\end{array}$ \\
\hline $\begin{array}{l}\text { How long the person has had the symptoms when they see the } \\
\text { primary care physician }\end{array}$ & $\begin{array}{l}3 \text { days } \\
7 \text { days } \\
10 \text { days }\end{array}$ & $\begin{array}{l}\text { Durations identified from literature [8], to cover a wide yet } \\
\text { realistic range for RTIs. }\end{array}$ \\
\hline Relevant comorbidities of the patient ${ }^{b}$ & $\begin{array}{l}\text { 1. None } \\
\text { 2. One } \\
\text { 3. Two or more }\end{array}$ & $\begin{array}{l}\text { Reflects clinical guideline CG69 [14], which identifies } \\
\text { comorbidities as a risk factor for developing complications, } \\
\text { and particularly for acute cough, increasing risk with additional } \\
\text { comorbidities or other patient factors. }\end{array}$ \\
\hline Length of the consultation with the primary care physician & $\begin{array}{l}5 \mathrm{~min} \\
10 \mathrm{~min} \\
15 \mathrm{~min}\end{array}$ & $\begin{array}{l}\text { Proxy for quality of information exchange between primary care } \\
\text { physician and patient. Levels represent plausible consultation } \\
\text { durations; the longest consultation is intended to allow for use of } \\
\text { tools such as TARGET patient leaflets [36] to explain treatment. }\end{array}$ \\
\hline Patient opinion on taking antibiotics ${ }^{b}$ & $\begin{array}{l}\text { 1. Preference to have antibiotics } \\
\text { 2. No preference expressed } \\
\text { 3. Preference not to have antibiotics }\end{array}$ & $\begin{array}{l}\text { Patient opinion can influence clinician choices [19,37]. Levels } \\
\text { allow for patient preference in either direction, or neutral. }\end{array}$ \\
\hline Risk of harm from not having antibiotic treatment straight away & $\begin{array}{l}1 \% \\
10 \% \\
20 \%\end{array}$ & $\begin{array}{l}\text { The GP's judgement of the risk of harm, explained as symptom } \\
\text { persistence or recurrence, or complications. Shown as a } \\
\text { percentage, as a graphic, and also described in words ('In } 1 \text { case } \\
\text { out of every } 100 \text { like this, the patient would ...'). } \\
\text { Levels identified from literature. Rates of complications typically } \\
\text { range from }<1 \% \text { to } 2 \% \text { for RTIs in primary care studies without } \\
\text { antibiotics [11,38-40]. Symptom persistence at follow-up in the } \\
\text { case of acute bronchitis ranges from } 18 \% \text { to } 35 \% \text { in meta-analyses } \\
\text { depending on the measure [41], with a reconsultation rate of } \\
\sim 20 \% \text { for non-resolution for RTIs [10,21], without antibiotics. }\end{array}$ \\
\hline Risk of an adverse effect from taking antibiotics & $\begin{array}{l}1 \% \\
10 \% \\
20 \%\end{array}$ & $\begin{array}{l}\text { The GP's judgement of the risk of adverse effect, explained as } \\
\text { allergy, side effects, or future resistance. Shown in three formats, } \\
\text { as above. } \\
\text { Levels identified from literature and public information on rates } \\
\text { of side effects and allergy }[8,42] \text {. }\end{array}$ \\
\hline How a delayed prescription would be provided ${ }^{b}$ & $\begin{array}{l}\text { 1: prescription plus advice to delay collection of antibiotics } \\
\text { 2: post-dated prescription } \\
\text { 3: collect prescription from the practice reception at a later date }\end{array}$ & $\begin{array}{l}\text { Policy relevance: these formats have been tested in clinical trials } \\
\text { [11] and referred to in guidelines [14], but there are no } \\
\text { quantitative data on clinician preferences. }\end{array}$ \\
\hline
\end{tabular}

${ }^{a}$ Explanations of each attribute and its levels were provided in the survey (see Supplementary Materials S1 Section 1). ${ }^{\mathrm{b}}$ Categorical variable. Other attributes are treated as continuous variables. 


\section{Results}

\subsection{Respondent Characteristics}

A total of 181 GPs completed the survey, with a median completion time of $17 \mathrm{~min}$. The sample was consistent with the target distributions for sex, age, country and practice size, reflecting the population of UK GPs (Table 2). One in five respondents reported finding the survey difficult to complete to some degree.

Half of the respondents were partners in their GP practice. The majority considered the practice where they work most often to be of medium level of deprivation, and average level of antibiotic prescribing. On average, respondents reported that $17 \%$ of their patients who present with an RTI leave with a delayed antibiotic prescription, but there was wide variation in prescribing patterns between individuals; eight respondents reported never using delayed antibiotic prescriptions for patients with RTIs.

Table 2. Respondent characteristics.

\begin{tabular}{|c|c|c|c|}
\hline \multicolumn{2}{|c|}{ Respondent Characteristic } & \multirow{2}{*}{$\begin{array}{c}\text { N (Percentage) } \\
98(54 \%)\end{array}$} & \multirow{2}{*}{$\frac{\text { Quota }(\%))^{\#}}{56}$} \\
\hline Sex & Male & & \\
\hline \multirow{5}{*}{ Age (years) } & 39 and under & $40(22 \%)$ & 26 \\
\hline & $40-49$ & $76(42 \%)$ & 41 \\
\hline & 50-59 & $50(28 \%)$ & 24 \\
\hline & 60 or over & $15(8 \%)$ & 10 \\
\hline & Median age & 46 & \\
\hline \multirow{4}{*}{ Country } & England & $152(84 \%)$ & 83 \\
\hline & Scotland & $17(9 \%)$ & 10 \\
\hline & Wales & $9(5 \%)$ & 4.5 \\
\hline & Northern Ireland & $3(2 \%)$ & 2.5 \\
\hline \multirow{7}{*}{ Practice size } & 1-2500 patients & $5(3 \%)$ & 4 \\
\hline & 2501-5000 & $28(15 \%)$ & 15 \\
\hline & $5001-7500$ & $40(22 \%)$ & 20 \\
\hline & $7501-10,000$ & $35(19 \%)$ & 20 \\
\hline & $10,001-12,500$ & $32(18 \%)$ & \\
\hline & $12,501-15,000$ & $14(8 \%)$ & 41 \\
\hline & More than 15,000 patients & $27(15 \%)$ & \\
\hline \multirow{3}{*}{ Role in practice } & Partner & $96(53 \%)$ & \\
\hline & Salaried GP & $57(31 \%)$ & \\
\hline & Locum & $28(15 \%)$ & \\
\hline \multirow{3}{*}{ Level of local deprivation * } & High & $49(27 \%)$ & \\
\hline & Medium & $72(40 \%)$ & \\
\hline & Low & $56(31 \%)$ & \\
\hline \multirow{3}{*}{$\begin{array}{l}\text { Practice's level of antibiotic } \\
\text { prescribing compared to } \\
\text { similar practices }\end{array}$} & Very low/Low & $36(20 \%)$ & \\
\hline & Average & $100(55 \%)$ & \\
\hline & Very high/high & $35(19 \%)$ & \\
\hline \multirow{5}{*}{$\begin{array}{l}\text { Usual format of delayed } \\
\text { prescription * }\end{array}$} & Standard prescription with recommendation to wait & $145(80 \%)$ & \\
\hline & Post-dated prescription & $23(13 \%)$ & \\
\hline & Electronic post-dated prescription & $7(4 \%)$ & \\
\hline & Prescription available from practice at future date & $4(2 \%)$ & \\
\hline & Other & $2(1 \%)$ & \\
\hline \multirow{3}{*}{$\begin{array}{l}\text { RTI prescribing }{ }^{*} \text { : mean } \\
\text { percentage of patients } \\
\text { who leave with } . .\end{array}$} & An immediate antibiotic prescription (range) & $31 \%(1$ to $90 \%)$ & \\
\hline & A delayed antibiotic prescription (range) & $17 \%$ (0 to $85 \%)$ & \\
\hline & No antibiotic prescription (range) & $52 \%(0$ to $95 \%)$ & \\
\hline \multirow{3}{*}{ Found the survey * } & Very easy/easy/quite easy & $90(50 \%)$ & \\
\hline & Neither easy nor difficult & $52(29 \%)$ & \\
\hline & Very difficult/difficult/quite difficult & $39(21 \%)$ & \\
\hline
\end{tabular}

\footnotetext{
\# Based on annual GP omnibus survey, by Medeconnect, the online survey provider. * Self-reported.
} 


\subsection{Importance Ranking of the Attributes}

Figure 1 shows the number of respondents who assigned each attribute a given rank, before completing the choice questions. Symptoms were the most important, followed by comorbidities, duration of illness and the risk of harm due to delaying treatment. Respondents ranked length of consultation, the format of the delayed prescription and patient preference as the least important.

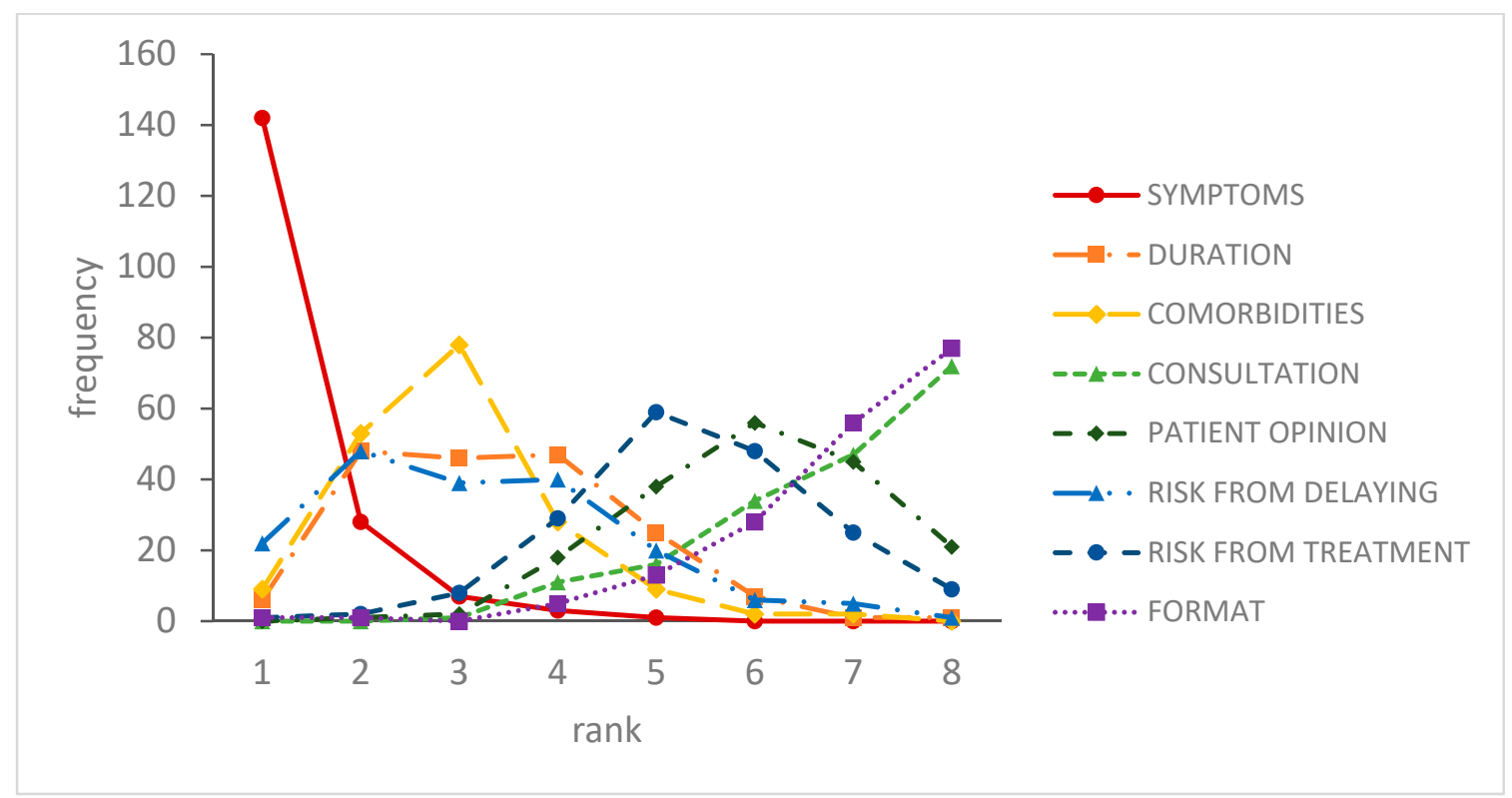

Figure 1. Ranking of attribute importance. Attribute descriptions: DURATION: duration of illness prior to consultation; CONSULTATION: length of consultation; PATIENT OPINION: preferences regarding antibiotics expressed by the patient; RISK FROM DELAYING: risk of harm from not starting antibiotics straight away; RISK FROM TREATMENT: risk of adverse effects from taking antibiotics; FORMAT: how the delayed prescription would be provided. Vertical axis indicates the number of respondents who ranked a given attribute at the rank shown on the horizontal axis ( 1 = highest rank).

\subsection{Choice Responses}

Each of the 181 GPs answered 15 choice questions, resulting in 2715 choice occasions. Initially, $68 \%$ of choices between delayed and immediate prescription were for a delayed prescription. When the no-prescription alternative was offered, 51\% (1393/2715) of choices were for this option, with the vast majority of those choices switching from an initial choice of delayed prescription (1383 of the 1393 no-prescription choices). This left $21 \%$ and $28 \%$ remaining with their original choice of delayed or immediate prescription respectively. Twenty-six respondents never chose a delayed prescription, with fewer never choosing immediate or no prescription (five and two respondents respectively), and 95\% of respondents choosing a delayed prescription six times or fewer. By question, the proportions choosing immediate and no prescription were inversely correlated. The trend in proportion choosing delayed prescription was less clear, but appeared to be higher in the scenarios where there was no strong preference for either immediate or no prescription (Figure 2). 


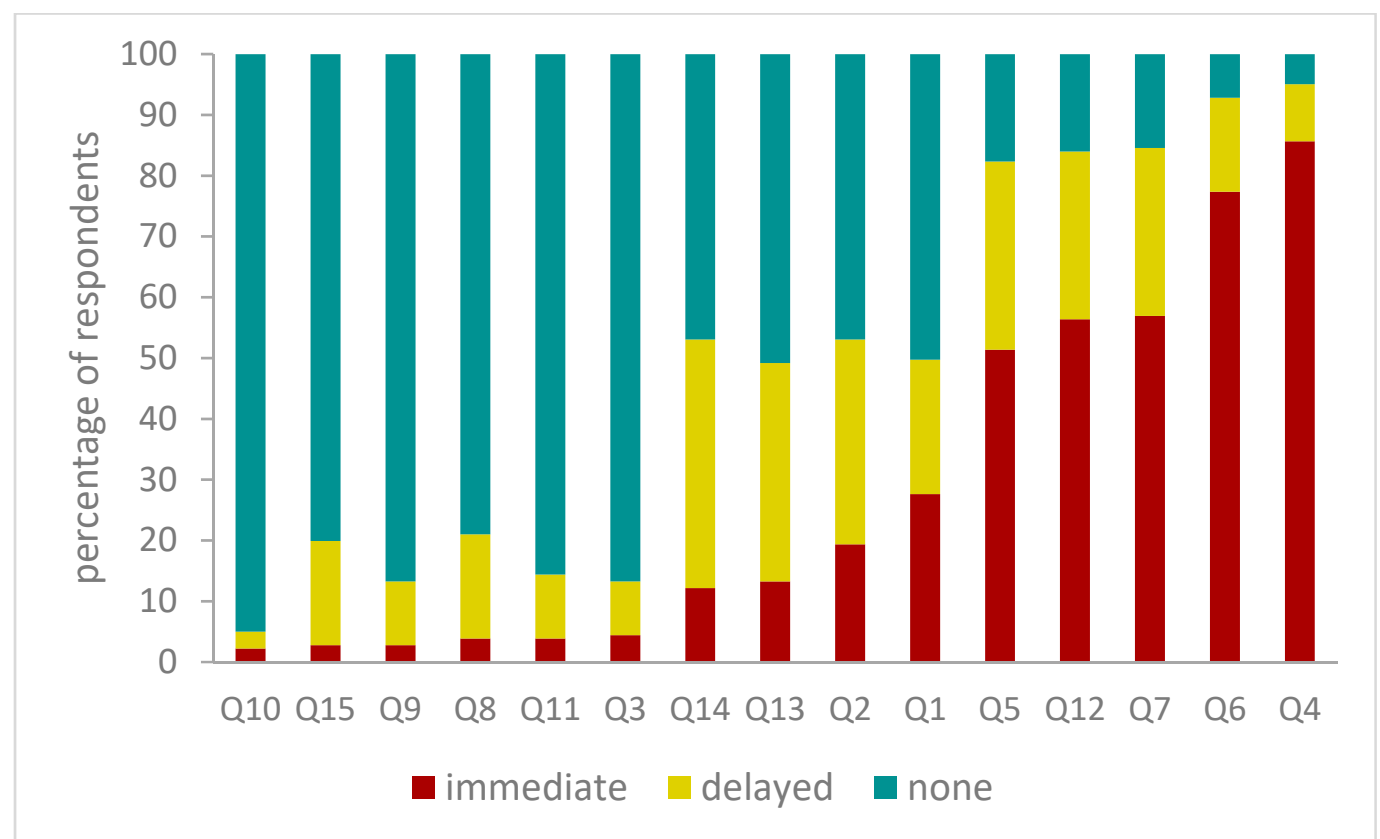

Figure 2. Proportions ultimately choosing immediate, delayed and no prescription per choice question. Q: choice question, numbered by the order in which they were presented to respondents. To illustrate the patterns in proportions choosing immediate, delayed, or no prescription, the graph orders the bars by the proportion ultimately choosing the immediate prescription.

\subsection{Choice Modelling}

Table 3 presents a mixed-effect logistic regression model, which estimates the effect of each of the scenario attributes on the likelihood of respondents choosing the delayed prescription option over an immediate prescription. By using a mixed-effect logistic regression, the model allows for differences between respondents in their tendency to choose the delayed prescription. The coefficients are all of the expected sign, giving the model face validity; that is, positive where we would expect an increase in the attribute to increase the likelihood of respondents choosing the delayed prescription, and negative where we would expect the likelihood to decrease. The attributes in the model explain $61 \%$ of the variation in responses; this rises to $65 \%$ when between-respondent heterogeneity is incorporated.

Respondents were more likely to choose the delayed prescription for the minor versions of both upper and lower respiratory tract symptoms. The probability of choosing the delayed prescription increased by 0.41 for productive cough and runny nose compared to the more serious lower tract symptoms, and by 0.54 for the minor throat symptoms compared to the more serious (for full table of the effects on the marginal probability of choosing delayed prescription including confidence intervals, see Supplementary Material S1 Section 2). Respondents were also more likely to choose the delayed prescription if the consultation was longer, or there was a higher risk of adverse events from taking antibiotics, but these effects were small (probability of choosing the delayed prescription increased by 0.005 per additional minute of consultation or 0.003 per $1 \%$ increase in risk of adverse effects). They were less likely to choose delayed prescription if the symptoms had been present for longer (probability decreased by 0.03 per day), if the patient had multiple comorbidities (probability decreased by 0.12 compared to no comorbidities), and with increasing risk of harm from delaying treatment (probability decreased by 0.01 per $1 \%$ increased risk). A delayed prescription was more likely if the patient expressed a preference not to take antibiotics (probability increased by 0.03 ), and conversely, less likely if the patient preferred to have antibiotics (probability decreased by 0.04). Compared to the most common format of delayed prescription (giving the patient a prescription with advice to wait), respondents were less likely to choose delayed prescription if the patient would have to return to the surgery to collect it (decrease in probability of choosing the delayed prescription of 0.04 ). 
Table 3. Effect of attributes on preferences for delayed prescription.

\begin{tabular}{|c|c|c|c|c|c|}
\hline \multicolumn{2}{|r|}{ Attribute/Level } & \multicolumn{2}{|c|}{ 1. Attributes Only } & \multicolumn{2}{|c|}{ 2. Respondent Characteristics } \\
\hline & & Coefficient & $95 \% \mathrm{CI}$ & Coefficient & $95 \% \mathrm{CI}$ \\
\hline \multirow{4}{*}{ Symptoms } & Sore and red throat, and swollen lymph nodes in the neck ('minor throat') & 3.17 & $\begin{array}{c}2.48 \text { to } 3.86 \\
p<0.001\end{array}$ & 3.17 & $\begin{array}{c}2.48 \text { to } 3.86 \\
p<0.001\end{array}$ \\
\hline & Productive cough and runny nose ('minor chest') & 3.47 & $\begin{array}{c}2.79 \text { to } 4.14 \\
p<0.001\end{array}$ & 3.47 & $\begin{array}{c}2.79 \text { to } 4.14 \\
p<0.001\end{array}$ \\
\hline & Sore throat, swollen lymph nodes in the neck, pyrexia and purulent tonsils ('serious throat') & -0.90 & $\begin{array}{c}-1.31 \text { to }-0.49 \\
p<0.001\end{array}$ & -0.90 & $\begin{array}{c}-1.31 \text { to }-0.49 \\
p<0.001\end{array}$ \\
\hline & Productive cough, pyrexia and pain on breathing ('serious chest') ${ }^{a}$ & 0 & - & 0 & - \\
\hline Symptom duration & Per day longer & -0.33 & $\begin{array}{c}-0.43 \text { to }-0.23 \\
p<0.001\end{array}$ & -0.33 & $\begin{array}{c}-0.43 \text { to }-0.23 \\
p<0.001\end{array}$ \\
\hline \multirow{3}{*}{ Relevant comorbidities } & None $^{\mathrm{a}}$ & 0 & - & 0 & - \\
\hline & One & 0.05 & $\begin{array}{c}-0.31 \text { to } 0.42 \\
p=0.769\end{array}$ & 0.06 & $\begin{array}{c}-0.31 \text { to } 0.42 \\
p=0.762\end{array}$ \\
\hline & Two or more & -1.18 & $\begin{array}{c}-1.64 \text { to }-0.72 \\
p<0.001\end{array}$ & -1.18 & $\begin{array}{c}-1.64 \text { to }-0.72 \\
p<0.001\end{array}$ \\
\hline Consultation length & Per minute longer & 0.05 & $\begin{array}{c}0.02 \text { to } 0.09 \\
p=0.003\end{array}$ & 0.05 & $\begin{array}{c}0.02 \text { to } 0.09 \\
p=0.003\end{array}$ \\
\hline \multirow{3}{*}{ Patient opinion } & Preference to have antibiotics & 0.39 & $\begin{array}{c}-0.72 \text { to }-0.05 \\
p=0.022\end{array}$ & -0.39 & $\begin{array}{c}-0.72 \text { to }-0.05 \\
p=0.023\end{array}$ \\
\hline & No preference expressed ${ }^{a}$ & 0 & - & 0 & - \\
\hline & Preference not to have antibiotics & 0.33 & $\begin{array}{c}0.05 \text { to } 0.60 \\
p=0.020\end{array}$ & 0.33 & $\begin{array}{c}0.05 \text { to } 0.60 \\
p=0.020\end{array}$ \\
\hline Risk of harm from not starting antibiotics & Per $1 \%$ higher & -0.13 & $\begin{array}{c}-0.17 \text { to }-0.10 \\
p<0.001\end{array}$ & -0.13 & $\begin{array}{c}-0.17 \text { to }-0.10 \\
p<0.001\end{array}$ \\
\hline Risk of adverse effect from taking antibiotics & Per $1 \%$ higher & 0.03 & $\begin{array}{c}0.01 \text { to } 0.05 \\
p=0.001\end{array}$ & 0.03 & $\begin{array}{c}0.01 \text { to } 0.05 \\
p=0.001\end{array}$ \\
\hline \multirow{3}{*}{ Format of the delayed prescription } & Advice to delay ${ }^{a}$ & 0 & - & 0 & - \\
\hline & Post-dated prescription & -0.03 & $\begin{array}{l}-0.37 \text { to } 0.31 \\
\quad p=0.872\end{array}$ & -0.03 & $\begin{array}{l}-0.37 \text { to } 0.31 \\
\quad p=0.872\end{array}$ \\
\hline & Collect from practice & -0.43 & $\begin{array}{c}-0.82 \text { to }-0.08 \\
p=0.016\end{array}$ & -0.45 & $\begin{array}{c}-0.82 \text { to }-0.08 \\
p=0.016\end{array}$ \\
\hline \multicolumn{2}{|c|}{ Self-reported prescribing behaviour: percent immediate prescriptions for RTI } & & & -0.02 & $\begin{array}{c}-0.04 \text { to }-0.01 \\
p=0.002\end{array}$ \\
\hline Intercept & & 2.23 & $\begin{array}{c}1.49 \text { to } 2.97 \\
p<0.001\end{array}$ & 3.44 & $\begin{array}{c}2.46 \text { to } 4.42 \\
p<0.001\end{array}$ \\
\hline $\operatorname{Var}\left(\right.$ intercept) ${ }^{b}$ & & 1.57 & 0.96 to 2.57 & 1.41 & 0.88 to 2.28 \\
\hline Pseudo $\mathrm{R}^{2}$ : attributes only & & 0.61 & & 0.62 & \\
\hline Pseudo $R^{2}$ : attributes and respondent-level effect & & 0.65 & & 0.66 & \\
\hline Akaike Information Criterion & & 1955 & & 1943 & \\
\hline Bayesian Information Criterion & & 2043 & & 2037 & \\
\hline
\end{tabular}

a Reference level for the categorical variables. The coefficient for each level shows the effect of that level on the log odds of choosing delayed prescription, relative to the reference level. ${ }^{b}$ Variance of the random intercept. This term reflects the unexplained variation between respondents in their tendency to choose the delayed prescription after accounting for explanatory variables listed in the table. CI, confidence interval. 
The relative strength of the attribute effects can be seen by comparing the magnitude of the coefficients. A patient expressing a preference to have antibiotics, for example, had a similar effect to an additional day of illness in reducing the probability of the GP choosing a delayed prescription. Similarly, a patient with a serious chest infection of a given duration, and a patient who had had a minor infection for 10 days longer, would have a similar probability of receiving a delayed prescription. The effect of a $1 \%$ difference in the risk from delaying antibiotics was approximately four-fold greater than the effect of a $1 \%$ difference in risks due to antibiotic treatment.

When respondent characteristics were added (Table 3), allowing for self-reported prescribing behaviour improved the fit of the model; respondents who reported a high level of immediate prescribing for RTIs in practice were more likely to choose the immediate prescription in the study. Although the effect per $1 \%$ difference in self-reported immediate prescribing was modest, the proportion of self-reported immediate prescriptions for RTI ranged from $1 \%$ to $90 \%$; at the mean value of $31 \%$ immediate prescriptions in practice, the effect was equivalent to 2.3 additional days of illness in reducing the likelihood of a delayed prescription. Other respondent characteristics showed no evidence of an effect on respondents' choices.

The model was robust to the exclusion of respondents who chose delayed prescription for the practice question $(n=27)$, chose the same response to all questions $(n=6)$, completed the survey in the fastest 1-5 percentiles $(n=9)$ or who reported that they found the survey 'quite difficult', 'difficult' or 'very difficult' $(n=39)$. The coefficients varied slightly, but the conclusions were unchanged.

An ordered logistic regression model allows for the additional choice of 'no prescription' (Figure 3). This assumes the three possible outcomes have a natural order (immediate, delayed, and no prescription) and models the probability of respondents choosing each outcome relative to the adjacent one in the hierarchy. Where the two coefficients for a given attribute are not significantly different $(p>0.05$, Wald test), those coefficients are assumed by the model to be equal (equal bars in Figure 3). Positive coefficients indicate that the attribute increased the likelihood of a reduced prescribing choice (no or delayed prescription), and negative coefficients indicate an increase in the likelihood of any prescription.

The direction and relative size of the effect of the attributes was similar to those described above (see Supplementary Material S1 Section 3 for a direct comparison). For most attributes, there was no difference between their effect on the decision between an immediate prescription and a reduced prescribing choice, and their effect on the decision to prescribe (delayed or immediate) or not. However, four of the coefficients suggested the attribute had a different effect depending on the type of decision being made. A patient expressing a preference to have antibiotics may influence the type of prescription, but there was no evidence that patient preferences affected the choice to prescribe at all. Similarly, minor symptoms had a stronger effect on the decision not to give an immediate prescription than on whether to prescribe at all. There was a minor difference in the effect of the risk of delaying treatment.

Figure 4 shows the probability of choosing each prescription type for each of the four types of symptoms presented in the survey, as predicted by the ordered logistic regression model. No prescription was the most likely choice for the minor symptoms, whilst an immediate prescription was most likely for the more serious symptoms. The proportion of delayed prescriptions remained almost constant across the four symptom levels. A similar pattern was seen for the other categorical attributes (see Supplementary Material S1 Section 4). 


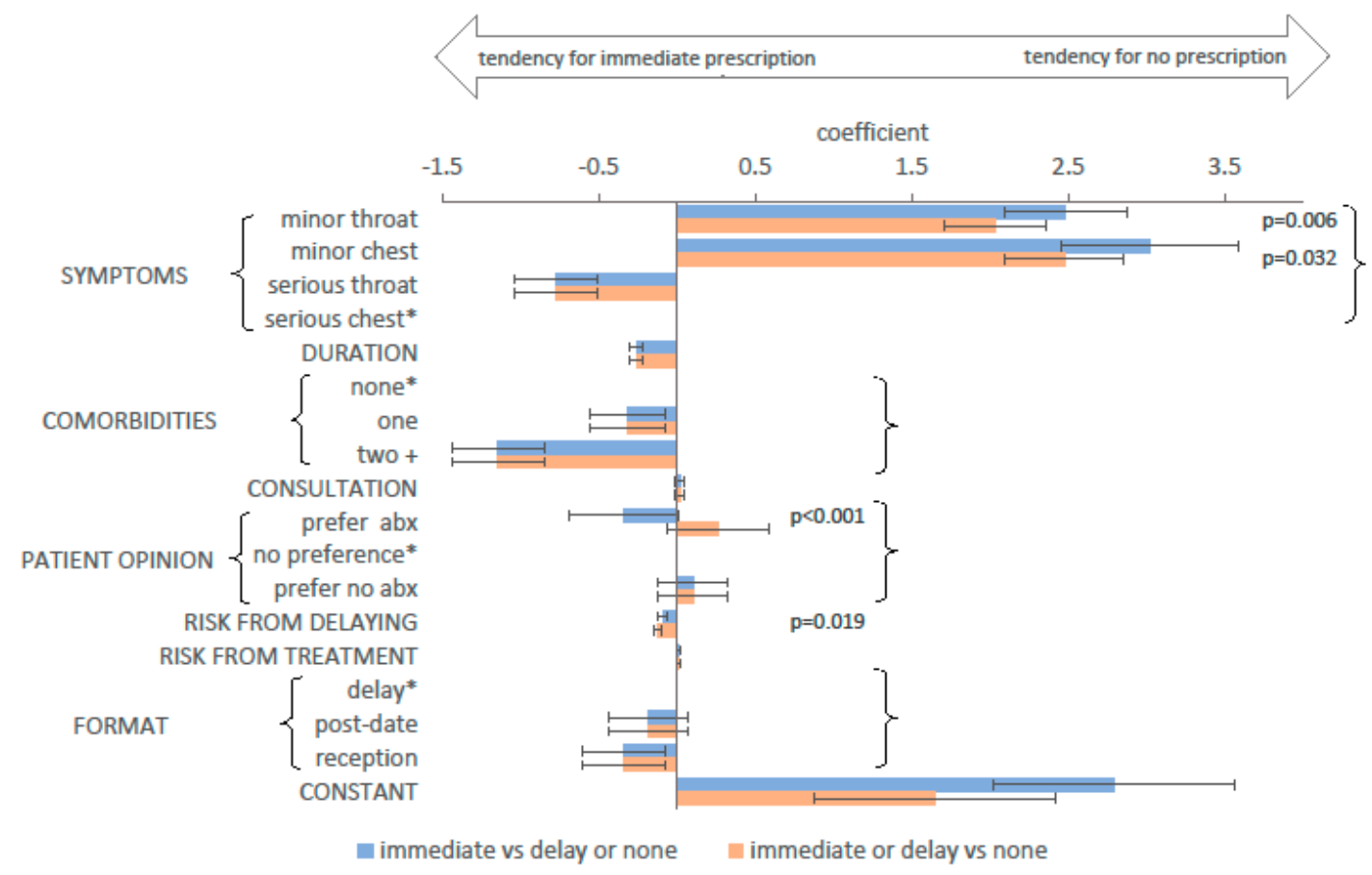

Figure 3. Coefficients for the ordered logistic regression model. Symptoms descriptions: minor throat—sore throat and swollen glands; minor chest—chesty cough and runny nose; serious throat—sore throat, swollen glands and fever; serious chest—chesty cough, fever and pain on breathing. * Reference level for categorical variables. $p$-values are shown where the coefficients differed $(p<0.05)$ between the choice to give an immediate prescription, and the choice to prescribe at all. For all other attributes and levels, the $p$-value for this difference was greater than 0.05 , and the coefficients were constrained to be equal in the model. Bars indicate $95 \%$ confidence intervals. Abbreviations: abx-antibiotics.

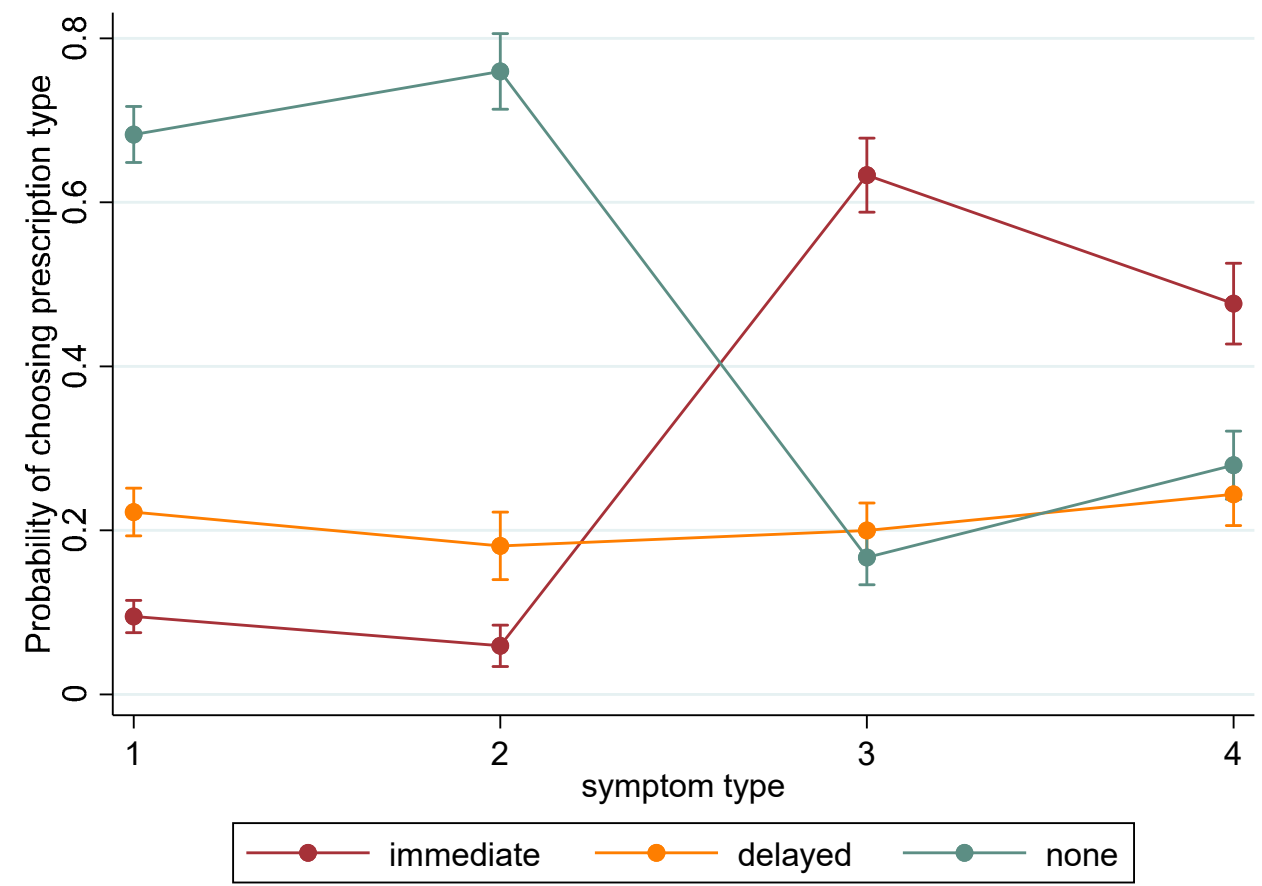

Figure 4. Probability of choosing immediate, delayed or no prescription, for each symptom type. Symptom descriptions: 1 minor throat-sore throat and swollen glands; 2 minor chest—chesty cough and runny nose; 3 serious throat-sore throat, swollen glands and fever; 4 serious chest—chesty cough, fever and pain on breathing. Bars indicate $95 \%$ confidence intervals. 


\section{Discussion}

Our study suggests that clinical indicators-presenting symptoms, duration of illness and patient comorbidities - are important factors in the decision to use delayed prescription. Patient preferences have some influence on the decision between immediate and delayed prescription, and GPs are less likely to use delayed prescription if the patient would have to come back to the practice to collect the prescription. The risk from delaying antibiotic treatment has a greater effect on the decision than the risk due to antibiotic treatment, demonstrating greater risk adversity regarding adverse outcomes than side effects. There is little effect of consultation length on prescription choice.

To our knowledge this is the first large-scale study to quantify the trade-offs made by UK GPs in considering delayed prescription. A smaller $(n=23)$ choice study of prescribing decisions among Australian GPs examined factors affecting antibiotic prescribing overall. Two attributes shared with our study (patient preferences and duration of illness) had significant effects in both studies; the effect of patient preferences was less in our study, possibly because of the strong effect of symptoms in our study, which were held constant in the Australian work [26]. Our findings are consistent with qualitative observations on the importance of perceived patient expectations in different countries [19,24-26,43,44]. These similarities suggest our results may be generalisable to other settings with similar primary healthcare systems.

The relative importance of the attributes from the regression models is broadly consistent with respondents' importance rankings. Both indicate that concerns about the potential for harm due to delaying antibiotics is more important in the prescribing decision than the risk of adverse effects due to taking antibiotics. This may reflect the doctor's role to treat patients, so the risk of a negative outcome from 'doing nothing' may be seen as worse than the risk of a negative outcome from giving treatment. Alternatively, it may be an acknowledgement that in a situation where antibiotics are indicated, the benefit from prescribing is accepted to outweigh the risk of harm from doing so. The length of the consultation was ranked low, consistent with its modest effect in the choice questions, despite concerns raised in qualitative studies over the time taken to explain the delayed prescription [19]. Our findings suggest that increasing the length of consultations to allow for the explanation required would not necessarily increase the uptake of delayed prescription.

Given the similarity of the coefficients in the two types of model, and the observation that the majority of 'no prescription' choices were originally for delayed prescription, we have not found a unique model for delayed prescription. Rather, our results appear to reflect a spectrum from immediate to no need for antibiotics, and our models indicate factors that move a GP's prescribing decision towards reduced prescribing - that is, to delayed or no prescription. This is perhaps consistent with findings in observational studies of delayed prescription, that the population of patients given a delayed prescription show a symptom distribution that is intermediate between those offered immediate or no prescription $[10,21]$. It may be that this rather loosely defined intermediate position contributes to the uncertainty in using delayed prescription noted by some GPs in qualitative work $[19,26]$, thus reducing its use.

The serious sore throat symptoms (sore throat, swollen glands and fever) had a greater negative effect on the likelihood of GPs using delayed or no prescription than serious chest symptoms (chesty cough, fever and pain on breathing). This is perhaps counter-intuitive given the potential seriousness of bacterial pneumonia, and may be due to variation in the way respondents interpreted the descriptions, for example assuming pneumonia had been excluded, or that the pain in breathing was due to coughing. Alternatively, respondents with recent experience with streptococcal pharyngitis or rising incidence of scarlet fever $[45,46]$, may have been sensitised to be more concerned about throat symptoms.

Based on our results, we suggest two possible approaches for continued reduction of antibiotic prescribing. First, our findings concur with other work recommending support for GPs in handling perceived patient pressure to prescribe $[23,26,47]$. In addition, we recommend patients are encouraged to express any preference not to have antibiotics (or a neutral opinion), and GPs to ask questions to establish that preference during the consultation. Although patients preferring not to have antibiotics 
was not consistently a strong factor in determining the prescribing decision in our models, we note that GPs' perceptions of patients' preferences are not necessarily accurate [48-51]. Hearing the patient's actual preference would avoid assumption that the patient expects antibiotics; this would also reduce concerns about delayed prescription giving an ambiguous message to the patient if it is clearly in line with the patient's preference.

Second, whilst symptoms and their duration are a key driver of prescribing behaviour, some GPs appear to be more averse to delayed or no antibiotic prescribing than would be expected from clinical evidence and guidelines. Reasons for this variation could include an individual's previous negative experience, tolerance of risk or ambiguity, or the mechanisms available for keeping up to date with data and guidelines. Raising awareness and understanding of the trial data supporting the use of delayed prescription may be helpful in reducing prescribing overall, including use of delayed prescription. A 'one-stop' website containing the key evidence for specific presentations, and current guidance, along with peer suggestions for explaining prescribing decisions to patients, may be helpful.

Some practitioners oppose the use of delayed prescription [52]. Two subgroups identified in our study could reflect views of this type: respondents who never chose the delayed prescription option in the study, and respondents who reported never using delayed antibiotic prescription in practice. There was minimal overlap between these two groups, and the groups were too small to draw any conclusions from our data. Further work to understand these polarised opinions would be helpful-particularly if they tend to be high prescribers-to identify alternative routes to support them in reducing antibiotic use.

\section{Limitations}

The study is limited by its hypothetical nature, meaning the responses may be idealised and not reflect actual practice. We suggest this may be particularly true of studies such as this where experts respond in their professional capacity, in contrast to general population or patient studies where we are seeking opinions; here, there may be consistency stemming from professional training or best practice guidance, and respondents might wish to reflect that in their responses. This may explain the relatively low heterogeneity of responses seen in this study. However, concerns that responses do not reflect actual practice are somewhat allayed by the observation that reported prescribing behaviour in practice not only varied widely, but was a significant predictor of responses to the choice questions.

Further, in constructing the scenarios, the number of attributes was inevitably constrained in order to manage respondent burden, and the scenarios may have omitted important features (for example, additional information about the patient, social factors, or clinical findings) that would affect the results. Our study included eight attributes; this is relatively high compared to studies among members of the public, which mostly use six or fewer [32,33,53], and a fifth of respondents reported finding the choices difficult. However, GPs are used to making complex decisions in their clinical practice; further, free-text comments on the survey did not raise complexity as an issue, and the relatively low heterogeneity of responses suggests that even if the choices were difficult, respondents were able to make consistent choices. Nonetheless, respondents may have used simplifying heuristics, such as ignoring certain attributes; for example, it is possible that respondents assessed the risk of recurrence or progression from the clinical features, and paid reduced attention to the attribute that quantified that risk.

Our choice question was presented in two parts, with the second allowing the option of no antibiotic prescription. This was to allow us to capture data on the choice between immediate and delayed prescription, our primary interest. However, it may not reflect the actual decision process in practice, which may have introduced bias to the choices. It may be that, having made a decision, respondents were more reluctant to change their mind and switch to 'no prescription', so overestimating the likelihood of prescribing an antibiotic and reducing the estimated impact of the attributes. However, the results show that $51 \%$ of choices switched in this way, suggesting it did not have a major impact.

The study design was optimised to quantify the main effects of the attributes, but did not allow for evaluation of interactions between the attributes. Some exploratory analyses were attempted, 
but the findings were difficult to interpret because of collinearity between the attributes. To explore the interactions effectively, future studies could use a blocked design, where a larger number of choice questions is generated, of which each respondent sees a randomly allocated subset [54].

Respondents were recruited by broad invitation to GP's who had signed up to be part of a panel. It is possible that those who chose to participate in this study had a particular interest in infectious disease, or antibiotic and resistance. Their level of knowledge may therefore not be representative of the broader population of GPs. Similarly, the offer of an incentive to participate (although this is normal) may have appealed to a particular population among GPs, although it is not obvious that the presence of an incentive would have affected respondents' answers in any particular direction in this study. Finally, the study was run before the COVID-19 pandemic, which led to a rapid shift to remote consultations; this change in practice may persist beyond the immediate lockdown restrictions. The effect of this may be reduced the certainty of prescribing in the absence of some physical examinations and face-to-face cues [55]. This could lead either to an increase in use of delayed prescription in response to that uncertainty, or to an increase in immediate prescriptions which could have important consequences for antimicrobial resistance. Future work is needed to identify any such changes in practice, and determine their effect on antibiotic consumption.

\section{Methods}

Study design, data collection and analysis followed good practice guidance for similar choice-based studies [56]. Ethical approval was granted by the University of Oxford Medical Sciences Interdivisional Research Ethics Committee (R58586/RE002). All respondents gave their informed consent before participating.

\subsection{Defining Survey Attributes and Levels}

Factors expected to influence GPs' use of delayed prescription (termed 'attributes') were identified from a literature search (summarised in the Supplementary Material S1 Section 5). Eight attributes were selected from this long-list based on: (a) importance of rankings from a convenience sample of practicing GPs $(n=4)$; (b) face validity based on the clinical experience within the project team; and (c) policy relevance.

Levels for each attribute were determined from clinical guidelines [14,15], Cochrane reviews $[8,41,57,58]$ and primary care studies $[11,21,38-40]$, current NHS prescribing tools and support materials $[36,59,60]$, and clinical expertise within the project team. Attributes, their levels, and rationale are shown in Table 1.

\subsection{Choice Questions}

Respondents (GPs) were asked to consider a consultation in which an adult patient presents with an RTI. In each choice question, they were presented with a profile describing the patient's condition, and asked to choose between immediate or delayed prescription. To allow for the possibility that some respondents would have chosen not to prescribe antibiotics at all in some of the scenarios described, they were then offered the choice to prescribe no antibiotics, or remain with their original choice. The 'no prescription' option was not presented initially, to avoid losing information on our primary question regarding preferences for delayed prescription as an alternative to immediate prescription.

\subsection{Survey and Experimental Design}

The survey was presented on-line, in English (full survey text provided in Supplementary Material S1 Section 1). Respondents were provided with information about the survey and gave their informed consent to participate. They were given instructions on how to complete the survey, and an explanation of each of the attributes. The next section asked respondents to rank the attributes in order of importance to the prescribing context (with the attributes presented in randomised order), and to 
complete a practice choice question, which consisted of the attribute levels most likely to lead to an 'immediate' prescription.

Respondents then completed 15 choice questions; this is generally considered an acceptable number of questions in this type of survey $[32,33,53,61,62]$. All respondents saw the same 15 questions. Finally, respondents answered questions about themselves, their practice and their antibiotic prescribing. The survey was reviewed with GPs on the project team at all stages of its construction, to ensure clarity and medical accuracy.

The choice questions were produced using experimental design software, Ngene [63], to create an efficient design (that is, one that maximises the information available from respondents' choices). Constraints were applied to avoid implausible scenarios (see Supplementary Material S1 Section 6). In line with recommended practice, an initial design was created, and used in a pilot sample (23 GPs recruited in the same way as for the main study). The choices from this pilot were used to optimise the design for the main study, but were not included in the final analysis. The most efficient design generated by the software was selected, following checks by clinical experts that none of the scenarios were implausible, nor were expected to lead to the same decision by all respondents.

A sample size estimate based on the standard errors predicted from the experimental design (52) indicated that at the target sample size of 180 , the study would be able to detect coefficients of value 0.24 for the levels of the symptoms attribute, and 0.01 for the other attributes, at a two-sided significance level of 0.05 and with power of $80 \%$.

\subsection{Data Collection}

Respondents were recruited from an existing panel of UK GPs curated by Medeconnect, a market research provider specialising in healthcare professionals. Quotas based on Medeconnect's annual GP Omnibus study were used to recruit a study sample representative of UK GPs in terms of gender, age, country within the UK and practice size. Respondents who completed the survey received reward points equivalent to $£ 20$ in the form of vouchers, which is in line with standard practice of this provider for this type and length of survey. The data were collected in February and March 2019. No response rate could be calculated, as it was not known how many people would have seen the invitation to participate on the provider's website.

\subsection{Analysis}

Data analysis was performed in Stata (v.15SE) [64]. Choices between delayed and immediate prescription were analysed using a mixed-effects logistic regression model, which models the log-odds of choosing delayed prescription as a linear combination of the attribute levels. This model was chosen because it allows for heterogeneity between respondents in their tendency to choose the delayed prescription (that is, it includes a random intercept per respondent), and can incorporate respondent characteristics directly as predictors. The coefficients represent the effect of one unit of the attribute on the log-odds of respondents choosing the delayed prescription. Cluster-robust standard errors were used throughout, to allow for the fact that each respondent contributes 15 responses. To assess whether the time and risk attributes could be appropriately represented as continuous variables with a linear relationship with the outcome, these attributes were also modelled as categorical variables (see Supplementary Material S1 Section 7).

For the second part of the question (including the no-prescription alternative) choices were modelled using a partial proportional ordered logit model (gologit2 command in Stata). This assumes the three possible outcomes have a natural order (immediate, delayed and no prescription) and models the probability of respondents choosing each outcome relative to the adjacent one in the hierarchy. The partial proportional model was chosen because it relaxes the assumption that each attribute has a consistent effect on the probability of choosing each category. The model generates two coefficients for each attribute: one for its effect on the probability of choosing an immediate prescription rather than delayed or no prescription, and one for its effect on the probability of choosing a prescription (either 
type) rather than no prescription. The two coefficients are tested to determine if they are statistically significantly different (Wald test, $p<0.05$ ) and if so, they are retained as different coefficients.

To help interpret model coefficients, the average predicted probability of choosing each type of prescription for each level (the marginal predicted mean) was calculated, using the 'margins' command in Stata. This method sets the attribute to that level for all observations, keeping the other variables at their observed levels. The probability of choosing delayed prescription is then predicted for each observation using the regression model, and the mean probability calculated. This can also be expressed as the effect of one unit of the attribute on the probability of choosing the delayed prescription.

Models were compared using a measure of how much of the variability in responses was explained by the model (McKelvey and Zavoina Pseudo- $R^{2}$ [65]) and measures of goodness-of-fit (the Akaike and Bayesian Information Criteria).

The dataset is available from the corresponding author on reasonable request.

\section{Conclusions}

Clinical features (symptoms, duration and comorbidities) are appropriately the most important factors for GPs in deciding between immediate, delayed and no antibiotic prescription. However, broader dissemination of the relevant clinical evidence for specific presentations may be helpful in supporting GPs to make greater use of delayed prescription. With patient opinion playing a role in the choice of prescription type, establishing a patient's actual preference during the consultation may also help to reduce the number of immediate prescriptions. Extending consultation duration appears unlikely to increase use of delayed prescription.

Supplementary Materials: The following are available online at http://www.mdpi.com/2079-6382/9/9/608/s1, Supplementary Materials S1.

Author Contributions: Conceptualization, L.M., J.B., L.S.J.R., K.B.P., J.V.R., A.S.W., S.W.; methodology, L.M., J.B., L.S.J.R., K.B.P., J.V.R., A.S.W., S.W.; software, L.M., J.B., L.S.J.R., K.B.P.; validation, J.B., L.S.J.R., K.B.P.; formal analysis, L.M., J.B., L.S.J.R., K.B.P., A.S.W., S.W.; investigation, L.M.; resources, C.C.B., B.H., M.V.M., S.T.-C., M.M., A.S.W.; data curation, L.M.; writing-original draft preparation, L.M.; writing-review and editing, L.M., J.B., L.S.J.R., K.B.P., C.C.B., B.H., M.V.M., S.T.-C., M.M., J.V.R., A.S.W., S.W.; visualization, L.M., J.B., L.S.J.R., K.B.P.; supervision, J.V.R., A.S.W., S.W.; project administration, L.M.; funding acquisition, L.S.J.R., C.C.B., B.H., M.V.M., S.T.-C., M.M., J.V.R., A.S.W., S.W. All authors have read and agreed to the published version of the manuscript.

Funding: The study was funded by the Economic and Social Research Council (ESRC) through the Antimicrobial Resistance Cross Council Initiative supported by the seven research councils in partnership with other funders (grant reference: ES/P008232/1). This study was also funded by the National Institute for Health Research (NIHR) Health Protection Research Unit in Healthcare Associated Infections and Antimicrobial Resistance at the University of Oxford in partnership with Public Health England (PHE) [grant numbers HPRU-2012-10041 and NIHR200915]. ASW and CCB are NIHR Senior Investigators. ASW, JB, LSJR and SW are supported by the NIHR Oxford Biomedical Research Centre. MMcL is supported by the NIHR Imperial Patient Safety Translational Research Centre.

Acknowledgments: The STEP-UP team consists of: Philip E Anyanwu, Aleksandra Borek, Nicole Bright, James Buchanan, Christopher Butler, Anne Campbell, Ceire Costelloe, Benedict Hayhoe, Alison Holmes, Susan Hopkins, Azeem Majeed, Monsey McLeod, Michael V Moore, Liz Morrell, Koen B Pouwels, Julie V Robotham, Laurence S J Roope, Sarah Tonkin-Crine, A. Sarah Walker, Sarah Wordsworth, Anna Zalevski. We thank all respondents who took part in our survey.

Conflicts of Interest: The authors declare no conflict of interest. The funders played no role in the design of the study, the collection, analysis, and interpretation of data, or in writing the manuscript. The views expressed are those of the authors and not necessarily those of the NHS, the NIHR, the Department of Health or PHE.

\section{Abbreviations}

abx antibiotics

GP general practitioner

NHS National Health Service

NICE National Institute for Health and Care Excellence

RTI respiratory tract infection 


\section{References}

1. O'Neill, J. Tackling Drug-Resistant Infections Globally: Final Report and Recommendations. Available online: https://wellcomecollection.org/works/thvwsuba (accessed on 1 May 2019).

2. Davies, S. Annual Report of the Chief Medical Officer 2011: Volume 2; Department of Health and Social Care: London, UK, 2013.

3. Public Health England. English Surveillance Programme for Antimicrobial Utilisation and Resistance (ESPAUR): Report 2018-2019. Available online: https://assets.publishing.service.gov.uk/government/uploads/ system/uploads/attachment_data/file/843129/English_Surveillance_Programme_for_Antimicrobial_ Utilisation_and_Resistance_2019.pdf (accessed on 20 February 2020).

4. OpenPrescribing.net, EBM DataLab, University of Oxford, Oxford. Available online: https://openprescribing. net/bnf/0501/ (accessed on 1 July 2020).

5. Smieszek, T.; Pouwels, K.B.; Dolk, F.C.K.; Smith, D.R.M.; Hopkins, S.; Sharland, M.; Hay, A.D.; Moore, M.V.; Robotham, J.V. Potential for reducing inappropriate antibiotic prescribing in English primary care. J. Antimicrob. Chemother. 2018, 73, ii36-ii43. [CrossRef] [PubMed]

6. Smith, D.R.M.; Dolk, F.C.K.; Pouwels, K.B.; Christie, M.; Robotham, J.V.; Smieszek, T. Defining the appropriateness and inappropriateness of antibiotic prescribing in primary care. J. Antimicrob. Chemother. 2018, 73, ii11-ii18. [CrossRef] [PubMed]

7. NICE. Quality Standard QS121: Antimicrobial Stewardship. Available online: https://www.nice.org.uk/ guidance/qs121/chapter/Quality-statement-2-Back-up-delayed-prescribing (accessed on 20 January 2020).

8. Spurling, G.K.; Del Mar, C.B.; Dooley, L.; Foxlee, R.; Farley, R. Delayed antibiotic prescriptions for respiratory infections. Cochrane Database Syst. Rev. 2017, 9, Cd004417. [CrossRef] [PubMed]

9. Arroll, B.; Kenealy, T.; Kerse, N. Do delayed prescriptions reduce antibiotic use in respiratory tract infections? A systematic review. Br. J. Gen. Pract. 2003, 53, 871-877.

10. Little, P.; Stuart, B.; Hobbs, F.D.R.; Butler, C.C.; Hay, A.D.; Delaney, B.; Campbell, J.; Broomfield, S.; Barratt, P.; Hood, K.; et al. Antibiotic prescription strategies for acute sore throat: A prospective observational cohort study. Lancet Infect. Dis. 2014, 14, 213-219. [CrossRef]

11. Little, P.; Moore, M.; Kelly, J.; Williamson, I.; Leydon, G.; McDermott, L.; Mullee, M.; Stuart, B. Delayed antibiotic prescribing strategies for respiratory tract infections in primary care: Pragmatic, factorial, randomised controlled trial. BMJ 2014, 348, g1606. [CrossRef] [PubMed]

12. Everitt, H.A.; Little, P.S.; Smith, P.W.F. A randomised controlled trial of management strategies for acute infective conjunctivitis in general practice. BMJ 2006, 333, 321. [CrossRef]

13. Little, P.; Moore, M.V.; Turner, S.; Rumsby, K.; Warner, G.; Lowes, J.A.; Smith, H.; Hawke, C.; Leydon, G.; Arscott, A.; et al. Effectiveness of five different approaches in management of urinary tract infection: Randomised controlled trial. BMJ 2010, 340, c199. [CrossRef]

14. NICE. Respiratory tract infections (self-limiting): Prescribing antibiotics. Clinical guideline (CG69). Available online: https://www.nice.org.uk/guidance/cg69 (accessed on 26 March 2018).

15. NICE. Sore throat (acute): Antimicrobial prescribing. NICE guideline (NG84). Available online: https: //www.nice.org.uk/guidance/ng84 (accessed on 20 May 2019).

16. NICE. Cough (acute): Antimicrobial prescribing. NICE guideline (NG120). Available online: https: //www.nice.org.uk/guidance/ng120/chapter/Recommendations\#treatment (accessed on 1 February 2020).

17. NICE. Urinary tract infection (lower): Antimicrobial prescribing. NICE guideline (NG109). Available online: https://www.nice.org.uk/guidance/ng109/chapter/Recommendations\#treatment-for-women-withlower-uti-who-are-not-pregnant (accessed on 1 February 2020).

18. NICE. Clinical Knowledge Summary-Conjunctivitis (infective). Available online: https://cks.nice.org.uk/ conjunctivitis-infective\#! scenario:1 (accessed on 30 January 2020).

19. Ryves, R.; Eyles, C.; Moore, M.; McDermott, L.; Little, P.; Leydon, G.M. Understanding the delayed prescribing of antibiotics for respiratory tract infection in primary care: A qualitative analysis. Bmj Open 2016, 6, e011882. [CrossRef]

20. Leydon, G.M.; Turner, S.; Smith, H.; Little, P. Women's views about management and cause of urinary tract infection: Qualitative interview study. BMJ 2010, 340, c279. [CrossRef] 
21. Little, P.; Stuart, B.; Smith, S.; Thompson, M.J.; Knox, K.; van den Bruel, A.; Lown, M.; Moore, M.; Mant, D. Antibiotic prescription strategies and adverse outcome for uncomplicated lower respiratory tract infections: Prospective cough complication cohort (3C) study. BMJ 2017, 357, j2148. [CrossRef] [PubMed]

22. Little, P.; Hobbs, F.R.; Moore, M.; Mant, D.; Williamson, I.; McNulty, C.; Lasseter, G.; Cheng, M.E.; Leydon, G.; McDermott, L.; et al. PRImary care Streptococcal Management (PRISM) study: In vitro study, diagnostic cohorts and a pragmatic adaptive randomised controlled trial with nested qualitative study and cost-effectiveness study. Health Technol. Assess. 2014, 18. [CrossRef] [PubMed]

23. Peters, S.; Rowbotham, S.; Chisholm, A.; Wearden, A.; Moschogianis, S.; Cordingley, L.; Baker, D.; Hyde, C.; Chew-Graham, C. Managing self-limiting respiratory tract infections: A qualitative study of the usefulness of the delayed prescribing strategy. Br. J. Gen. Pract. 2011, 61, e579-e589. [CrossRef] [PubMed]

24. Raft, C.F.; Bjerrum, L.; Arpi, M.; Jarlov, J.O.; Jensen, J.N. Delayed antibiotic prescription for upper respiratory tract infections in children under primary care: Physicians' views. Eur. J. Gen. Pract. 2017, 23, 190-195. [CrossRef]

25. Sargent, L.; McCullough, A.; Del Mar, C.; Lowe, J. Using theory to explore facilitators and barriers to delayed prescribing in Australia: A qualitative study using the Theoretical Domains Framework and the Behaviour Change Wheel. Bmc Fam. Pract. 2017, 18, 20. [CrossRef]

26. Lum, E.P.M.; Page, K.; Whitty, J.A.; Doust, J.; Graves, N. Antibiotic prescribing in primary healthcare: Dominant factors and trade-offs in decision-making. Infect. Dis. Health 2018, 23, 74-86. [CrossRef]

27. Pouwels, K.B.; Dolk, F.C.K.; Smith, D.R.M.; Smieszek, T.; Robotham, J.V. Explaining variation in antibiotic prescribing between general practices in the UK. J. Antimicrob. Chemother. 2018, 73, ii27-ii35. [CrossRef] [PubMed]

28. Dolk, F.C.K.; Pouwels, K.B.; Smith, D.R.M.; Robotham, J.V.; Smieszek, T. Antibiotics in primary care in England: Which antibiotics are prescribed and for which conditions? J. Antimicrob. Chemother. 2018, 73, ii2-ii10. [CrossRef] [PubMed]

29. Gulliford, M.C.; Dregan, A.; Moore, M.V.; Ashworth, M.; Staa, T.v.; McCann, G.; Charlton, J.; Yardley, L.; Little, P.; McDermott, L. Continued high rates of antibiotic prescribing to adults with respiratory tract infection: Survey of 568 UK general practices. Bmj Open 2014, 4, e006245. [CrossRef]

30. Pouwels, K.B.; Dolk, F.C.K.; Smith, D.R.M.; Robotham, J.V.; Smieszek, T. Actual versus 'ideal' antibiotic prescribing for common conditions in English primary care. J. Antimicrob. Chemother. 2018, 73, 19-26. [CrossRef]

31. Macfarlane, J.; Holmes, W.; Gard, P.; Macfarlane, R.; Rose, D.; Weston, V.; Leinonen, M.; Saikku, P.; Myint, S. Prospective study of the incidence, aetiology and outcome of adult lower respiratory tract illness in the community. Thorax 2001, 56, 109-114. [CrossRef] [PubMed]

32. Buchanan, J.; Wordsworth, S.; Schuh, A. Patients' Preferences for Genomic Diagnostic Testing in Chronic Lymphocytic Leukaemia: A Discrete Choice Experiment. Patient Patient Cent. Outcomes Res. 2016, 9, 525-536. [CrossRef] [PubMed]

33. Rowen, D.; Brazier, J.; Mukuria, C.; Keetharuth, A.; Risa Hole, A.; Tsuchiya, A.; Whyte, S.; Shackley, P. Eliciting Societal Preferences for Weighting QALYs for Burden of Illness and End of Life. Med Decis Mak. 2016, 36, 210-222. [CrossRef] [PubMed]

34. Regier, D.A.; Diorio, C.; Ethier, M.-C.; Alli, A.; Alexander, S.; Boydell, K.M.; Gassas, A.; Taylor, J.; Kellow, C.; Mills, D.; et al. Discrete Choice Experiment to Evaluate Factors That Influence Preferences for Antibiotic Prophylaxis in Pediatric Oncology. PLoS ONE 2012, 7, e47470. [CrossRef] [PubMed]

35. Little, P.; Hobbs, F.D.R.; Moore, M.; Mant, D.; Williamson, I.; McNulty, C.; Cheng, Y.E.; Leydon, G.; McManus, R.; Kelly, J.; et al. Clinical score and rapid antigen detection test to guide antibiotic use for sore throats: Randomised controlled trial of PRISM (primary care streptococcal management). BMJ 2013, 347, f5806. [CrossRef]

36. Royal College of General Practitioners. TARGET Antibiotic Toolkit. Available online: https://www.rcgp.org. uk/clinical-and-research/resources/toolkits/target-antibiotic-toolkit.aspx (accessed on 20 May 2019).

37. Fletcher-Lartey, S.; Yee, M.; Gaarslev, C.; Khan, R. Why do general practitioners prescribe antibiotics for upper respiratory tract infections to meet patient expectations: A mixed methods study. Bmj Open 2016, 6, e012244. [CrossRef]

38. Arroll, B.; Kenealy, T.; Kerse, N. Do delayed prescriptions reduce the use of antibiotics for the common cold? A single-blind controlled trial. J. Fam. Pract. 2002, 51, 324-328. [PubMed] 
39. Little, P.; Rumsby, K.; Kelly, J.; Watson, L.; Moore, M.; Warner, G.; Fahey, T.; Williamson, I. Information Leaflet and Antibiotic Prescribing Strategies for Acute Lower Respiratory Tract InfectionA Randomized Controlled Trial. JAMA 2005, 293, 3029-3035. [CrossRef]

40. Little, P.; Stuart, B.; Hobbs, F.D.R.; Butler, C.C.; Hay, A.D.; Campbell, J.; Delaney, B.; Broomfield, S.; Barratt, P.; Hood, K.; et al. Predictors of suppurative complications for acute sore throat in primary care: Prospective clinical cohort study. Bmj Br. Med. J. 2013, 347, f6867. [CrossRef]

41. Smith, S.M.; Fahey, T.; Smucny, J.; Becker, L.A. Antibiotics for acute bronchitis. Cochrane Database Syst. Rev. 2017, 6, CD000245. [CrossRef]

42. NHS England. Side effects-Antibiotics. Available online: https://www.nhs.uk/conditions/antibiotics/sideeffects/ (accessed on 11 June 2019).

43. Saliba-Gustafsson, E.A.; Roing, M.; Borg, M.A.; Rosales-Klintz, S.; Lundborg, C.S. General practitioners' perceptions of delayed antibiotic prescription for respiratory tract infections: A phenomenographic study. PLoS ONE 2019, 14, e0225506. [CrossRef] [PubMed]

44. De la Poza Abad, M.; Mas Dalmau, G.; Gich Saladich, I.; Martínez García, L.; Llor, C.; Alonso-Coello, P. Use of delayed antibiotic prescription in primary care: A cross-sectional study. Bmc Fam. Pract. 2019, $20,45$. [CrossRef] [PubMed]

45. Guy, R.; Williams, C.; Irvine, N.; Reynolds, A.; Coelho, J.; Saliba, V.; Thomas, D.; Doherty, L.; Chalker, V.; von Wissmann, B.; et al. Increase in scarlet fever notifications in the United Kingdom, 2013/2014. Eurosurveillance 2014, 19, 20749. [CrossRef] [PubMed]

46. Lamagni, T.; Guy, R.; Chand, M.; Henderson, K.L.; Chalker, V.; Lewis, J.; Saliba, V.; Elliot, A.J.; Smith, G.E.; Rushton, S.; et al. Resurgence of scarlet fever in England, 2014-16: A population-based surveillance study. Lancet Infect. Dis. 2018, 18, 180-187. [CrossRef]

47. Francis, N.A.; Gillespie, D.; Nuttall, J.; Hood, K.; Little, P.; Verheij, T.; Goossens, H.; Coenen, S.; Butler, C.C. Delayed antibiotic prescribing and associated antibiotic consumption in adults with acute cough. Br. J. Gen. Pract. 2012, 62, e639-e646. [CrossRef]

48. Macfarlane, J.; Holmes, W.; Macfarlane, R.; Britten, N. Influence of patients' expectations on antibiotic management of acute lower respiratory tract illness in general practice: Questionnaire study. BMJ 1997, 315, 1211-1214. [CrossRef]

49. Butler, C.C.; Rollnick, S.; Pill, R.; Maggs-Rapport, F.; Stott, N. Understanding the culture of prescribing: Qualitative study of general practitioners' and patients' perceptions of antibiotics for sore throats. BMJ 1998, 317, 637-642. [CrossRef]

50. Linder, J.A.; Singer, D.E. Desire for antibiotics and antibiotic prescribing for adults with upper respiratory tract infections. J. Gen. Intern. Med. 2003, 18, 795-801. [CrossRef]

51. Hoye, S.; Frich, J.C.; Lindbaek, M. Use and feasibility of delayed prescribing for respiratory tract infections: A questionnaire survey. BMC Fam Pract. 2011, 12, 34. [CrossRef]

52. Rowe, T.A.; Linder, J.A. Delayed Antibiotic Prescriptions in Ambulatory Care: Reconsidering a Problematic Practice. JAMA 2020. [CrossRef]

53. Erdem, S.; Thompson, C. Prioritising health service innovation investments using public preferences: A discrete choice experiment. BMC Health Serv. Res. 2014, 14, 360. [CrossRef] [PubMed]

54. Rose, J.M.; Bliemer, M.C.J. Constructing Efficient Stated Choice Experimental Designs. Transp. Rev. 2009, 29, 587-617. [CrossRef]

55. Hayhoe, B.; Greenfield, G.; Majeed, A. Is it getting easier to obtain antibiotics in the UK? Br. J. Gen. Pract. 2019, 69, 54-55. [CrossRef] [PubMed]

56. Bridges, J.F.P.; Hauber, A.B.; Marshall, D.; Lloyd, A.; Prosser, L.A.; Regier, D.A.; Johnson, F.R.; Mauskopf, J. Conjoint Analysis Applications in Health-A Checklist: A Report of the ISPOR Good Research Practices for Conjoint Analysis Task Force. Value Health 2011, 14, 403-413. [CrossRef] [PubMed]

57. Kenealy, T.; Arroll, B. Antibiotics for the common cold and acute purulent rhinitis. Cochrane Database Syst. Rev. 2013. [CrossRef] [PubMed]

58. Spinks, A.; Glasziou, P.P.; Del Mar, C.B. Antibiotics for sore throat. Cochrane Database Syst. Rev. 2013. [CrossRef]

59. DeShazo, J.R.; Fermo, G. Designing Choice Sets for Stated Preference Methods: The Effects of Complexity on Choice Consistency. J. Environ. Econ. Manag. 2002, 44, 123-143. [CrossRef] 
60. McNulty, C.; Hawking, M.; Lecky, D.; Jones, L.; Owens, R.; Charlett, A.; Butler, C.; Moore, P.; Francis, N. Effects of primary care antimicrobial stewardship outreach on antibiotic use by general practice staff: Pragmatic randomized controlled trial of the TARGET antibiotics workshop. J. Antimicrob. Chemother. 2018, 73, 1423-1432. [CrossRef]

61. Skedgel, C.; Wailoo, A.; Akehurst, R. Societal preferences for distributive justice in the allocation of health care resources: A latent class discrete choice experiment. Med. Decis. Mak. 2015, 35, 94-105. [CrossRef] [PubMed]

62. Shah, K.K.; Tsuchiya, A.; Wailoo, A.J. Valuing health at the end of life: A stated preference discrete choice experiment. Soc. Sci. Med. 2015, 124, 48-56. [CrossRef]

63. ChoiceMetrics. Ngene 1.1.1 User Manual E Reference Guide; ChoiceMetrics: St Leonards, Australia, 2012.

64. StataCorp. Stata Statistical Software: Release 15; StataCorp LP: College Station, TX, USA, 2017.

65. McKelvey, R.D.; Zavoina, W. A statistical model for the analysis of ordinal level dependent variables. J. Math. Sociol. 1975, 4, 103-120. [CrossRef]

(C) 2020 by the authors. Licensee MDPI, Basel, Switzerland. This article is an open access article distributed under the terms and conditions of the Creative Commons Attribution (CC BY) license (http://creativecommons.org/licenses/by/4.0/). 